\title{
Prostate cancer patients may have an increased risk of coexisting advanced colorectal neoplasms
}

This article was published in the following Dove Press journal:

OncoTargets and Therapy

9 September 2016

Number of times this article has been viewed

\section{Sun-Hye Ko ${ }^{1,2}$ \\ Myong Ki Baeg2,3 \\ Woong Jin $\mathrm{Bae}^{4}$ \\ Pumsoo $\mathrm{Kim}^{3}$ \\ Myung-Gyu Choi ${ }^{2}$}

'Department of Internal Medicine, Asan Medical Center, University of Ulsan College of Medicine, Seoul, South Korea; ${ }^{2}$ Department of Internal Medicine, College of Medicine, The Catholic University of Korea, Seoul, South Korea; ${ }^{3}$ Department of Internal Medicine, International St Mary's Hospital, Catholic Kwandong University, Incheon, South Korea; ${ }^{4}$ Department of Urology, College of Medicine, The Catholic University of Korea, Seoul, South Korea
Correspondence: Myong Ki Baeg Catholic Kwandong University, International St Mary's Hospital, Simgokro I00gil 25 Seo-Gu, Incheon 227II, South Korea

Tel +82322902923

Email baegmk@gmail.com
Background/aims: Patients being treated for prostate cancer $(\mathrm{PCa})$ have an increased risk of developing colorectal cancer. However, whether PCa patients are inherently at a higher risk of colorectal neoplasms (CRNs) is unknown. We aimed to investigate the risk of CRNs in PCa patients.

Materials and methods: Patients who had been diagnosed with PCa at a tertiary medical center and had colonoscopy within 1 year of the PCa diagnosis were investigated. Patients were propensity-matched 1:2 by age and body mass index to asymptomatic control subjects who had undergone colonoscopy for routine health screening. CRN was defined as histological confirmation of an adenoma or adenocarcinoma component. Advanced CRN was defined as any of the following: 1) histological findings of high-grade dysplasia, 2) inclusion of villous features, 3) tumor $\geq 1 \mathrm{~cm}$ in size, or 4) presence of an adenocarcinoma. Risk factors for CRN and advanced CRN were evaluated by univariate and multivariate analysis.

Results: A total of 191 patients diagnosed with PCa had colonoscopies within 1 year of PCa diagnosis. Of these, 23 patients with a history of previous malignancy and seven with incomplete colonoscopies were excluded, leaving 161 patients in the PCa group. Although presence of PCa was not a significant risk factor for $\mathrm{CRN}$ by multivariate analysis, $\mathrm{PCa}$ was a significant risk factor for advanced CRN (odds ratio [OR] 3.300; 95\% confidence interval [CI] 1.766-6.167; $P<0.001$ ). Other significant risk factors for advanced CRN were age (OR 1.050; 95\% CI 1.003-1.009; $P=0.036)$ and body mass index (OR $1.205 ; 95 \%$ CI $1.067-1.361 ; P=0.003$ ), whereas aspirin use (OR $0.414 ; 95 \%$ CI $0.173-0.990 ; P=0.047$ ) was a preventive factor.

Conclusion: The risk of advanced CRN may be significantly increased in patients with $\mathrm{PCa}$. Patients with PCa should have a colonoscopy at the time of PCa diagnosis.

Keywords: colorectal neoplasms, prostate cancer, colonoscopy, colorectal adenoma and carcinoma

\section{Introduction}

With the introduction of prostate-specific antigen (PSA) screening in clinical practice, the number of patients with prostate cancer (PCa) has rapidly increased. ${ }^{1}$ PSA screening, combined with improvements in therapeutic modalities, has led to an increase in long-term survival. ${ }^{2}$ The long-term survival of PCa patients, older age at diagnosis, and increased cancer risk associated with PCa therapy has led to a focus on secondary primary malignancies (SPMs) ${ }^{3-8}$

One sixth of PCa patients have been reported to have an SPM. ${ }^{9}$ Among the various types of SPMs reported in PCa patients, colorectal cancer is clinically significant as its risk can be increased by PCa treatment. ${ }^{5-8}$ This becomes even more important when considering that colorectal cancer and PCa have been reported to confer increased risks to each other. ${ }^{9-12}$ This increase in risk may be due to shared risk factors between 
the two malignancies, such as obesity, consumption of meat, lack of exercise, vitamin D deficiency, and statin or aspirin use. ${ }^{13-22}$ The two malignancies also share genetic risk factors such as BRCA1 and BRCA2, Lynch syndrome, and genes associated with the Wnt pathway. ${ }^{23-28}$

Colorectal adenomas (CRAs) are considered precursors to colorectal cancer and the two share many risk factors. ${ }^{29,30}$ Colonoscopic screening and removal of CRAs has been reported to reduce long-term colorectal cancer mortality. ${ }^{31}$ However, whether the prevalence of colorectal neoplasms (CRNs; colorectal cancers and adenomas) is increased in PCa patients and whether such patients would benefit from screening colonoscopy has not been investigated. Therefore, the aim of our study was to analyze the colonoscopy results of PCa patients at the time of diagnosis and to determine whether the risk of CRN is increased in these patients.

\section{Methods}

\section{Subjects}

We retrospectively evaluated the medical records of patients who had been diagnosed with PCa at Seoul St Mary's Hospital, a tertiary referral center, from January 2008 to April 2014. We included PCa patients who had undergone colonoscopic examination within 1 year of $\mathrm{PCa}$ diagnosis. Patients were excluded if they had any of the following: 1) incomplete colonoscopic examination, 2) history of inflammatory bowel disease, 3) family history of cancer syndromes or polyposis, or 4) previous history of colon polypectomy. The control subjects were randomly selected by systematic sampling from 13,530 asymptomatic males who had received a colonoscopy for health screening during the same period and were propensity-matched 1:2 to the $\mathrm{PCa}$ group by age and body mass index (BMI).

Subjects were excluded from the control group if they had any of the following: 1) incomplete colonoscopic examination, 2) any symptom of colorectal disease (abdominal pain, bowel habit change, hematochezia), 3) previous history of colon cancer, or 4) previous colon polypectomy. Use of subject data was approved by the institutional review board of Seoul St Mary's Hospital (KC14RISI0802) which waived the requirement for subject consent forms as this was a retrospective study using blinded data.

\section{Colonoscopy}

All colonoscopies were performed by endoscopists who were certified as experts by the Korean Society of Gastrointestinal Endoscopy using standard procedures after routine preparation with $4 \mathrm{~L}$ of polyethylene glycol. Small polyps $(<0.5 \mathrm{~cm})$ were removed using cold or hot biopsy forceps, and large polyps ( $\geq 0.5 \mathrm{~cm}$ ) were removed by snare polypectomy or endoscopic mucosal resection. The size of the polyps was measured endoscopically based on visual estimation and comparison with biopsy forceps. ${ }^{32}$ The locations of the resected lesions were classified as right colon (ascending and transverse colon), left colon (descending and rectosigmoid colon), or both. All retrieved polyps were reviewed by an experienced gastrointestinal pathologist.

\section{Definition of CRN, advanced neoplasm, and colorectal cancer}

CRN was defined as a histologically confirmed adenoma or adenocarcinoma component. Non-neoplastic polyps such as inflammatory or hyperplastic polyps and mucosal tags were excluded. Subjects with $\geq 3$ CRNs were classified as having multiple lesions. Patients were classified into the advanced CRN group if they met the criteria for advanced adenoma classification of the 2012 American Gastroenterological Association Guidelines as follows: 1) high-grade dysplasia, 2) villous features, 3) size $\geq 1 \mathrm{~cm}$, or 4) presence of an adenocarcinoma. ${ }^{33}$

\section{Selection of data for analysis}

Medical charts of the patient and control groups were reviewed. These data included age, BMI, history of diabetes mellitus, hypertension, dyslipidemia, smoking, alcohol consumption, and aspirin intake. Laboratory data included the levels of total cholesterol and PSA. In the PCa group, the TNM stage was reclassified according to the American Joint Cancer Committee (7th edition) based on laboratory, pathology, operation, and radiology records. ${ }^{34}$ In PCa patients who received colonoscopy, the reasons for the colonoscopy, such as routine health screening or evaluation of symptoms (hematochezia, bloating, abdominal pain, diarrhea, anemia, or constipation), and abnormal radiologic findings during PCa evaluation were recorded. In PCa patients, the time from PCa diagnosis to the colonoscopy examination was also noted.

\section{Statistical analysis}

PCa subjects were compared with age- and BMI-matched controls. A subgroup analysis comparing asymptomatic PCa subjects with age- and BMI-matched controls was also performed. Comparisons of continuous variables were assessed using Student's $t$-test, and categorical variables were examined using the $\chi^{2}$ test. Multivariate analysis of the risk factors for CRN or advanced CRN was performed using logistic regression. The odds ratios (ORs) and 95\% confidence intervals (CIs) were calculated for each variable 
in the multivariate analysis. All tests were two-sided and were performed at the $5 \%$ level of significance using SAS software (SAS Institute Inc., Cary, NC, USA).

\section{Results}

During the study period, 191 PCa patients had colonoscopies performed within 1 year of PCa diagnosis. Thirty patients were excluded from analysis for the following reasons: 23 had another previous malignancy and seven had incomplete examinations. The remaining 161 subjects were compared with 322 matched controls. The control group had a significantly higher percentage of subjects with diabetes, alcohol and smoking history, and higher total cholesterol levels (Table 1).

When the colonoscopic findings of the two groups were compared, the $\mathrm{PCa}$ group had a significantly higher number of polyps and CRNs per subject. The percentage of subjects with multiple CRNs and advanced CRNs was higher in the PCa group. There was no significant difference in the location of CRNs (Table 2).

Univariate and multivariate analysis was performed to identify the risk factors for overall CRNs and advanced CRNs. Higher BMI and history of smoking were significant risk factors for overall CRNs. For advanced CRNs, the presence of PCa (OR 2.545, 95\% CI 1.418-4.566, $P=0.002$ ), older age, and higher BMI were significant risk factors whereas aspirin use was a preventive factor (Table 3 ). When the risk factors were analyzed in patients aged $\leq 75$ years, the presence of PCa remained a significant risk factor for advanced CRNs (OR 3.331, 95\% CI 1.749-6.345, $P<0.001$ ).

Analysis of PCa patients was performed to identify the risk factors for CRNs among this population. Age and BMI were significant risk factors by univariate analysis although age was the only significant risk factor by multivariate analysis. There were no significant differences between $\mathrm{PCa}$

Table I Baseline characteristics of study subjects

\begin{tabular}{|c|c|c|c|}
\hline & $\begin{array}{l}\text { Prostate cancer } \\
\text { group }(n=161)\end{array}$ & $\begin{array}{l}\text { Control group } \\
(n=322)\end{array}$ & $P$-value \\
\hline Age (years) mean \pm SD & $67.8 \pm 7.3$ & $66.6 \pm 6.7$ & 0.060 \\
\hline BMI $\left(\mathrm{kg} / \mathrm{m}^{2}\right)$ mean $\pm \mathrm{SD}$ & $23.9 \pm 2.7$ & $23.8 \pm 2.6$ & 0.898 \\
\hline Diabetes (n, \%) & 19 (11.8\%) & 67 (20.8\%) & 0.015 \\
\hline Hypertension (n, \%) & $76(47.2 \%)$ & I4I (43.8\%) & 0.477 \\
\hline Aspirin use (n, \%) & $33(20.5 \%)$ & $83(25.8 \%)$ & 0.200 \\
\hline Alcohol (n, \%) & $66(41.0 \%)$ & $209(64.9 \%)$ & $<0.001$ \\
\hline Smoking (n, \%) & $38(23.6 \%)$ & $160(49.7 \%)$ & $<0.001$ \\
\hline $\begin{array}{l}\text { Total cholesterol } \\
(\mathrm{mg} / \mathrm{dL}) \text { mean } \pm \mathrm{SD}\end{array}$ & $179.8 \pm 32.8$ & $189.9 \pm 37.6$ & 0.003 \\
\hline $\mathrm{PSA}(\mathrm{ng} / \mathrm{mL})$ mean $\pm \mathrm{SD}$ & $73.7 \pm 471.0$ & $1.3 \pm 1.4$ & 0.053 \\
\hline
\end{tabular}

Abbreviations: BMI, body mass index; PSA, prostate-specific antigen; SD, standard deviation.
Table 2 Comparison of colonoscopic findings between the two groups

\begin{tabular}{|c|c|c|c|}
\hline & $\begin{array}{l}\text { Prostate } \\
\text { cancer group } \\
(n=161)\end{array}$ & $\begin{array}{l}\text { Control } \\
\text { group } \\
(n=322)\end{array}$ & $P$-value \\
\hline $\begin{array}{l}\text { Subjects with colon } \\
\text { polyps }(\mathrm{n}, \%)\end{array}$ & $109(67.7 \%)$ & $222(68.9 \%)$ & 0.782 \\
\hline $\begin{array}{l}\text { Mean number of polyps } \\
\text { (mean } \pm \text { SD) }\end{array}$ & $2.3 \pm 2.2$ & $1.8 \pm 3.2$ & 0.048 \\
\hline $\begin{array}{l}\text { Subjects with colon } \\
\text { neoplasms }(\mathrm{n}, \%)\end{array}$ & $95(59.0 \%)$ & $168(52.2 \%)$ & 0.155 \\
\hline $\begin{array}{l}\text { Mean number of neoplasms } \\
\text { per subject (mean } \pm \text { SD) }\end{array}$ & $1.6 \pm 2.3$ & $1.1 \pm 1.6$ & 0.016 \\
\hline $\begin{array}{l}\text { Subjects with multiplicity } \\
(>2)(n, \%)\end{array}$ & $38(23.6 \%)$ & $46(14.3 \%)$ & 0.011 \\
\hline $\begin{array}{l}\text { Subjects with Rt colon } \\
\text { neoplasms (n, \%) }\end{array}$ & $40(24.8 \%)$ & $70(21.7 \%)$ & 0.443 \\
\hline $\begin{array}{l}\text { Subjects with Lt colon } \\
\text { neoplasms }(\mathrm{n}, \%)\end{array}$ & $22(13.7 \%)$ & $46(14.3 \%)$ & 0.853 \\
\hline $\begin{array}{l}\text { Subjects with both side } \\
\text { neoplasms }(n, \%)\end{array}$ & $33(20.5 \%)$ & $53(16.5 \%)$ & 0.274 \\
\hline $\begin{array}{l}\text { Number of subjects with } \\
\text { advanced neoplasms (n, \%) }\end{array}$ & $29(18.0 \%)$ & 19 (5.9\%) & $<0.001$ \\
\hline Size $\geq I \mathrm{~cm}(\mathrm{n}, \%)$ & $29(18.0 \%)$ & $18(5.6 \%)$ & $<0.001$ \\
\hline High-grade dysplasia (n, \%) & $7(4.3 \%)$ & $2(1.0 \%)$ & 0.008 \\
\hline Villous features $(\mathrm{n}, \%)$ & $5(3.1 \%)$ & $3(1.0 \%)$ & 0.124 \\
\hline Carcinoma (n, \%) & $9(5.6 \%)$ & $0(0.0 \%)$ & $<0.001$ \\
\hline
\end{tabular}

Abbreviations: $\mathrm{Rt}$, right; $\mathrm{Lt}$, left.

patients with and without CRNs with respect to TNM stage, PSA levels, and reasons for colonoscopy (Table 4).

Subgroup analysis comparing asymptomatic $\mathrm{PCa}$ patients with age- and BMI-matched controls found that PCa subjects had significantly higher numbers of polyps and CRNs per subject. PCa subjects had a higher proportion of multiple and advanced CRNs (Table 5). Multivariate analysis found that higher BMI was a significant risk factor for CRNs, while PCa increased the risk but was not significant (OR 1.734, 95\% CI 0.998-3.012, $P=0.054$ ). In the case of advanced CRNs, both PCa (OR 4.188, 95\% CI 1.461-12.003, $P=0.008)$ and higher BMI were significant risk factors (Table 6).

\section{Discussion}

The risks of a primary malignancy occurring in sites other than the colon have been reported to be increased in patients with CRNs. ${ }^{35-37}$ However, the associations between PCa and CRNs have not been extensively investigated. One Swedish study studied the familial association of CRAs with other malignancies and found that families with $\mathrm{PCa}$ had an increased incidence of CRAs. ${ }^{37}$ To the best of our knowledge, our study is the first to directly investigate the association between CRNs and PCa. The presence of PCa 
Table 3 Risk factors for colorectal neoplasm in all patients (prostate cancer patients and controls)

\begin{tabular}{|c|c|c|c|c|c|c|c|c|c|c|c|c|}
\hline & \multicolumn{6}{|c|}{ Overall CRN } & \multicolumn{6}{|c|}{ Advanced CRN } \\
\hline & \multicolumn{3}{|c|}{ Univariate analysis } & \multicolumn{3}{|c|}{ Multivariate analysis } & \multicolumn{3}{|c|}{ Univariate analysis } & \multicolumn{3}{|c|}{ Multivariate analysis } \\
\hline & OR & $95 \% \mathrm{Cl}$ & $P$-value & OR & $95 \% \mathrm{Cl}$ & $P$-value & OR & $95 \% \mathrm{Cl}$ & P-value & OR & $95 \% \mathrm{Cl}$ & $P$-value \\
\hline Prostate cancer & 1.319 & $0.900-1.935$ & 0.156 & 1.438 & $0.963-2.145$ & 0.076 & 3.504 & $1.897-6.417$ & $<0.001$ & 3.300 & $1.766-6.167$ & $<0.001$ \\
\hline Age & 1.020 & $0.993-1.047$ & 0.145 & 1.027 & $0.999-1.055$ & 0.055 & 1.038 & $0.993-1.085$ & 0.097 & 1.050 & $1.003-1.009$ & 0.036 \\
\hline BMI & 1.065 & $0.995-|| 4 \mid$. & 0.069 & 1.081 & $1.008-1.160$ & 0.029 & 1.152 & I.029-I.290 & 0.014 & 1.205 & $|.067-| .36 \mid$ & 0.003 \\
\hline Diabetes & 0.954 & $0.598-1.523$ & 0.843 & & & & 0.769 & $0.333-1.778$ & 0.540 & & & \\
\hline HTN & $\mathrm{I} .138$ & $0.794-1.633$ & 0.481 & & & & I.04I & $0.572-1.895$ & 0.894 & & & \\
\hline Smoking & 1.349 & $0.935-1.944$ & 0.109 & I.577 & I.072-2.322 & 0.021 & 0.842 & $0.455-1.557$ & 0.583 & & & \\
\hline Alcohol & 1.080 & $0.752-1.550$ & 0.677 & & & & 0.969 & $0.532-1.768$ & 0.919 & & & \\
\hline Aspirin & 1.088 & $0.715-1.656$ & 0.695 & & & & 0.511 & $0.223-1.171$ & 0.113 & 0.414 & $0.173-0.990$ & 0.047 \\
\hline Total cholesterol & 0.999 & $0.994-1.004$ & 0.747 & & & & 0.996 & $0.987-1.004$ & 0.304 & & & \\
\hline PSA & 1.000 & $0.999-1.001$ & 0.971 & & & & 1.000 & $0.999-1.001$ & 0.877 & & & \\
\hline
\end{tabular}

Abbreviations: BMI, body mass index; HTN, hypertension; PSA, prostate-specific antigen; CRN, colorectal neoplasm; OR, odds ratio; Cl, confidence interval.

conferred a 3.3-fold increased risk of advanced CRNs compared with asymptomatic controls, even though the control group had significantly higher baseline risk factors such as diabetes, alcohol and smoking history, and total cholesterol levels. Our data suggest that screening colonoscopy should be considered at the time of PCa diagnosis.
Previous studies have shown that patients with $\mathrm{PCa}$ or colorectal cancer (CRC) are at increased risk for the other cancer. ${ }^{9-12}$ This increase in risk may be attributable to increased diagnostic or surveillance activity at or after PCa diagnosis; however, one case-controlled study reported that patients with CRC have an increased risk for PCa regardless

Table 4 Risk factors for colorectal neoplasm in prostate cancer patients

\begin{tabular}{|c|c|c|c|c|c|c|}
\hline & \multicolumn{3}{|l|}{ Univariate analysis } & \multicolumn{3}{|c|}{ Multivariate analysis } \\
\hline & $\begin{array}{l}\text { Prostate cancer } \\
\text { patients without } \\
\text { CRN }(n=66)\end{array}$ & $\begin{array}{l}\text { Prostate cancer } \\
\text { patients with } \\
\text { CRN }(n=95)\end{array}$ & $P$-value & OR & $95 \% \mathrm{Cl}$ & $P$-value \\
\hline Age (years) mean $\pm S D$ & $66.9 \pm 1.0$ & $68.5 \pm 0.7$ & 0.185 & 1.061 & $1.009-1.115$ & 0.020 \\
\hline BMI $\left(\mathrm{kg} / \mathrm{m}^{2}\right)$ mean $\pm \mathrm{SD}$ & $23.4 \pm 0.3$ & $24.2 \pm 0.3$ & 0.046 & 1.140 & $0.997-1.304$ & 0.055 \\
\hline Diabetes (n) & 7 & 12 & 0.695 & & & \\
\hline Hypertension (n) & 27 & 49 & 0.182 & & & \\
\hline Smoking (n) & 16 & 23 & 0.996 & & & \\
\hline Alcohol (n) & 28 & 38 & 0.758 & & & \\
\hline Aspirin use (n) & 14 & 19 & 0.851 & & & \\
\hline TNM stage $(n)$ & & & 0.130 & & & \\
\hline 1 & 7 & 2 & & & & \\
\hline $2 a$ & 8 & 8 & & & & \\
\hline $2 b$ & 26 & 46 & & & & \\
\hline 3 & 14 & 26 & & & & \\
\hline 4 & 11 & 13 & & & & \\
\hline Gleason score & & & 0.177 & & & \\
\hline 6 & 17 & 14 & & & & \\
\hline 7 & 31 & 61 & & & & \\
\hline 8 & 11 & II & & & & \\
\hline 9 & 6 & 6 & & & & \\
\hline 10 & 0 & I & & & & \\
\hline $\begin{array}{l}\text { Total cholesterol } \\
(\mathrm{mg} / \mathrm{dL}) \text { mean } \pm \mathrm{SD}\end{array}$ & $177.2 \pm 4.3$ & $181.6 \pm 3.2$ & 0.405 & & & \\
\hline $\mathrm{PSA}(\mathrm{ng} / \mathrm{mL})$ mean $\pm \mathrm{SD}$ & $83.5 \pm 61.5$ & $66.9 \pm 46.4$ & 0.827 & & & \\
\hline CFS reason $(n)$ & & & 0.061 & & & \\
\hline $\begin{array}{l}\text { Asymptomatic health } \\
\text { check-up }\end{array}$ & 32 & 49 & & & & \\
\hline Abdominal symptoms & 27 & 25 & & & & \\
\hline Suspicion of CRN & 7 & 21 & & & & \\
\hline
\end{tabular}

Abbreviations: BMI, body mass index; CFS, colonofibroscopy; CRN, colorectal neoplasm; PSA, prostate-specific antigen; OR, odds ratio; Cl, confidence interval. 
Table 5 Comparison of colonoscopic findings in asymptomatic prostate cancer patients and age- and BMI-matched controls

\begin{tabular}{|c|c|c|c|}
\hline & $\begin{array}{l}\text { Prostate } \\
\text { cancer group } \\
(n=81)\end{array}$ & $\begin{array}{l}\text { Control } \\
\text { group } \\
(n=162)\end{array}$ & $P$-value \\
\hline $\begin{array}{l}\text { Subjects with colon } \\
\text { polyps }(n, \%)\end{array}$ & $58(71.6 \%)$ & 105 (64.8\%) & 0.288 \\
\hline $\begin{array}{l}\text { Mean number of } \\
\text { polyps mean } \pm S D\end{array}$ & $2.3 \pm 3.2$ & $1.5 \pm 1.8$ & 0.033 \\
\hline $\begin{array}{l}\text { Subjects with colon } \\
\text { neoplasms (n, \%) }\end{array}$ & $49(60.5 \%)$ & 77 (47.5\%) & 0.057 \\
\hline $\begin{array}{l}\text { Mean number of neoplasms } \\
\text { per subject mean } \pm S D\end{array}$ & $1.5 \pm 2.1$ & $0.9 \pm 1.4$ & 0.022 \\
\hline $\begin{array}{l}\text { Subjects with multiplicity } \\
(>2)(n, \%)\end{array}$ & $17(21.0 \%)$ & 17 (10.5\%) & 0.026 \\
\hline $\begin{array}{l}\text { Subjects with Rt colon } \\
\text { neoplasms (n, \%) }\end{array}$ & 17 (21.0\%) & $34(21.0 \%)$ & 1.000 \\
\hline $\begin{array}{l}\text { Subjects with Lt colon } \\
\text { neoplasms (n, \%) }\end{array}$ & $12(14.8 \%)$ & $23(14.2 \%)$ & 0.897 \\
\hline $\begin{array}{l}\text { Subjects with both side } \\
\text { neoplasms ( } \mathrm{n}, \%)\end{array}$ & $20(24.7 \%)$ & $2 \mathrm{I}(13.0 \%)$ & 0.021 \\
\hline $\begin{array}{l}\text { Number of subjects with } \\
\text { advanced neoplasms ( } \mathrm{n}, \%)\end{array}$ & II (I3.6\%) & $6(3.7 \%)$ & 0.004 \\
\hline Size $\geq I \mathrm{~cm}(\mathrm{n}, \%)$ & $12(14.8 \%)$ & $6(3.7 \%)$ & 0.002 \\
\hline High-grade dysplasia (n, \%) & $2(2.5 \%)$ & $0(0 \%)$ & 0.110 \\
\hline Villous features (n, \%) & $3(3.7 \%)$ & $0(0 \%)$ & 0.036 \\
\hline Carcinoma (n, \%) & $2(2.5 \%)$ & $0(0 \%)$ & 0.110 \\
\hline
\end{tabular}

of the PCa screening status..$^{10}$ Another cancer registrybased Swiss study reported that the diagnosis of SPMs was reduced during the first 4 years after $\mathrm{PCa}$ diagnosis but the risk for SPM, including CRC, increased over time. ${ }^{38}$ These studies suggest that although detection bias may contribute to $\mathrm{CRC}$ risk in $\mathrm{PCa}$ patients, other underlying mechanisms may exist.

Another explanation for the increased risk of advanced CRN in PCa patients may be shared epidemiologic or genetic risk factors. Insulin-like growth factors and associated diseases such as obesity and metabolic syndrome have been associated with both $\mathrm{CRN}$ and $\mathrm{PCa} .{ }^{39}$ This association was also seen in our study, with subjects with higher BMI having significantly higher risks of advanced CRNs among both $\mathrm{PCa}$ patients and controls. Other risk factors such as consumption of red meat, vitamin D deficiency, lack of exercise, or medications such as aspirin or statins have also been associated with both CRN and PCa risk. ${ }^{1416-22}$ Unfortunately, although aspirin use was a significant preventive factor, due to the retrospective nature of our study we were not able to fully address all of these risk factors. Genetic risk factors such as BRCA1/2 and Lynch syndrome have also been associated with both CRN and $\mathrm{PCa} .{ }^{23-26}$ Although we excluded subjects with familial cancer syndromes or polyposis, the retrospective nature of our study made it difficult to fully evaluate family history of cancer. Family medical history should be detailed in further prospective studies to discover whether there is a clustering of patients with CRNs and PCa, as has been suggested. ${ }^{37}$

Interestingly, despite the significant association between $\mathrm{CRNs}$ and $\mathrm{PCa}$, PSA was not a significant risk factor for CRNs. This may be because PSA is exclusively secreted by the prostate gland, limiting the interaction between PSA and CRNs. ${ }^{40}$ Another possibility is that many PCa patients have normal PSA levels ${ }^{41}$ which may have contributed to our study results.

The clinical significance of undergoing colonoscopy at the time of PCa diagnosis must be further investigated. The long-term survival of $\mathrm{PCa}$ patients and the relatively older age at diagnosis increases the likelihood of PCa patients having SPMs such as CRC. ${ }^{2-4}$ The possible increase in CRC risk induced by $\mathrm{PCa}$ therapy further increases the necessity of preventing CRNs from advancing to $\mathrm{CRCs} .{ }^{5-8}$ Current guidelines partially support this as PCa patients are recommended

Table 6 Risk factors for colorectal neoplasm in asymptomatic prostate cancer patients and age- and BMI-matched controls

\begin{tabular}{|c|c|c|c|c|c|c|c|c|c|c|c|c|}
\hline & \multicolumn{6}{|c|}{ Overall CRN } & \multicolumn{6}{|c|}{ Advanced CRN } \\
\hline & \multicolumn{3}{|c|}{ Univariate analysis } & \multicolumn{3}{|c|}{ Multivariate analysis } & \multicolumn{3}{|c|}{ Univariate analysis } & \multicolumn{3}{|c|}{ Multivariate analysis } \\
\hline & OR & $95 \% \mathrm{Cl}$ & P-value & OR & $95 \% \mathrm{Cl}$ & $P$-value & OR & $95 \% \mathrm{Cl}$ & $P$-value & OR & $95 \% \mathrm{Cl}$ & P-value \\
\hline Prostate cancer & 1.690 & $0.983-2.906$ & 0.058 & $\mathrm{I} .734$ & $0.998-3.012$ & 0.054 & 4.086 & I.453-1I.489 & 0.008 & 4.188 & $1.46 \mid-12.003$ & 0.008 \\
\hline Age & 1.019 & $0.983-1.056$ & 0.303 & & & & 1.019 & $0.949-1.093$ & 0.607 & & & \\
\hline BMI & 1.122 & $1.020-1.234$ & 0.018 & 1.125 & $1.021-1.239$ & 0.017 & 1.254 & $1.050-1.498$ & 0.012 & 1.255 & $1.047-1.504$ & 0.014 \\
\hline Diabetes & 0.913 & $0.475-1.755$ & 0.786 & & & & 0.967 & $0.268-3.520$ & 0.959 & & & \\
\hline HTN & 1.222 & $0.736-2.030$ & 0.438 & & & & 1.120 & $0.417-3.008$ & 0.822 & & & \\
\hline Smoking & 1.085 & $0.649-1.812$ & 0.756 & & & & 0.794 & $0.284-2.224$ & 0.661 & & & \\
\hline Alcohol & 1.130 & $0.676-1.891$ & 0.641 & & & & 0.556 & $0.207-1.496$ & 0.245 & & & \\
\hline Aspirin & 0.721 & $0.398-1.309$ & 0.262 & & & & 0.415 & $0.092-1.870$ & 0.252 & & & \\
\hline Total cholesterol & 1.001 & $0.994-1.008$ & 0.730 & & & & 1.004 & $0.991-1.017$ & 0.579 & & & \\
\hline PSA & $\mid .021$ & $0.99|-| .05 \mid$ & 0.171 & & & & 0.997 & $0.959-1.038$ & 0.901 & & & \\
\hline
\end{tabular}

Abbreviations: BMI, body mass index; HTN, hypertension; PSA, prostate-specific antigen; CRN, colorectal neoplasm; OR, odds ratio; Cl, confidence interval. 
to follow colonoscopy screening guidelines for higher risk individuals. ${ }^{42}$ Furthermore, a recent study reported that the rate of unnecessary rectal biopsies and the associated risk of major complications were higher in PCa patients who underwent colonoscopy after brachytherapy compared to those who underwent colonoscopy at PCa diagnosis. ${ }^{43}$ However, whether colonoscopic screening with $\mathrm{CRN}$ removal at $\mathrm{PCa}$ diagnosis reduces $\mathrm{CRC}$ risk, even in patients undergoing potential $\mathrm{CRC}$-inducing therapy, requires further long-term prospective evaluation.

Our study has some limitations. First, the relatively small sample size may limit the generalizability of our findings. Second, PCa subjects were compared with asymptomatic controls, which may have introduced a selection bias. However, to cover this, we performed a subgroup analysis on asymptomatic PCa patients with age- and BMI-matched controls. PCa continued to be a significant risk factor for advanced CRNs while it increased the risk of overall CRNs but was not statistically significant. This suggests that the presence of $\mathrm{PCa}$ is associated with increased advanced CRN risk, regardless of the diagnostic circumstance.

In conclusion, our study demonstrated that the risk of concomitant advanced CRNs at the time of diagnosis may be increased in PCa patients. Further prospective long-term studies must be carried out to determine whether colonoscopic screening and removal of CRNs at the time of $\mathrm{PCa}$ diagnosis leads to a reduction in CRC.

\section{Acknowledgments}

This work was supported through the research fund of Catholic Kwandong University, International St Mary's Hospital.

\section{Disclosure}

The authors have no conflict of interest to disclose.

\section{References}

1. Cuzick J, Thorat MA, Andriole G, et al. Prevention and early detection of prostate cancer. Lancet Oncol. 2014;15(11):e484-e492.

2. Etzioni R, Gulati R, Tsodikov A, et al. The prostate cancer conundrum revisited: treatment changes and prostate cancer mortality declines. Cancer. 2012;118(23):5955-5963.

3. DeSantis CE, Lin CC, Mariotto AB, et al. Cancer treatment and survivorship statistics, 2014. CA Cancer J Clin. 2014;64(4): 252-271.

4. Ferlay J, Shin HR, Bray F, Forman D, Mathers C, Parkin DM. Estimates of worldwide burden of cancer in 2008: GLOBOCAN 2008. Int J Cancer. 2010;127(12):2893-2917.

5. Gillessen S, Templeton A, Marra G, Kuo YF, Valtorta E, Shahinian VB. Risk of colorectal cancer in men on long-term androgen deprivation therapy for prostate cancer. J Natl Cancer Inst. 2010;102(23): 1760-1770.
6. Pickles T, Phillips N. The risk of second malignancy in men with prostate cancer treated with or without radiation in British Columbia, 1984-2000. Radiother Oncol. 2002;65(3):145-151.

7. Zelefsky MJ, Pei X, Teslova T, et al. Secondary cancers after intensitymodulated radiotherapy, brachytherapy and radical prostatectomy for the treatment of prostate cancer: incidence and cause-specific survival outcomes according to the initial treatment intervention. BJU Int. 2012;110(11):1696-1701.

8. Moon K, Stukenborg GJ, Keim J, Theodorescu D. Cancer incidence after localized therapy for prostate cancer. Cancer. 2006;107(5):991-998.

9. Van Hemelrijck M, Drevin L, Holmberg L, Garmo H, Adolfsson J, Stattin P. Primary cancers before and after prostate cancer diagnosis. Cancer. 2012;118(24):6207-6216.

10. Ozden N, Saruc M, Smith LM, Sanjeevi A, Roy HK. Increased cumulative incidence of prostate malignancies in colorectal cancer patients. Int J Gastrointest Cancer. 2003;34(1):49-54.

11. Moot AR, Polglase A, Giles GG, Garson OM, Thursfield V, Gunter D. Men with colorectal cancer are predisposed to prostate cancer. ANZ J Surg. 2003;73(5):289-293.

12. Liu L, de Vries E, Louwman M, et al. Prevalence of multiple malignancies in the Netherlands in 2007. Int J Cancer. 2011;128(7):1659-1667.

13. Buschemeyer WC 3rd, Freedland SJ. Obesity and prostate cancer: epidemiology and clinical implications. Eur Urol. 2007;52(2):331-343.

14. Watson AJ, Collins PD. Colon cancer: a civilization disorder. Dig Dis. 2011;29(2):222-228.

15. Sinha R, Park Y, Graubard BI, et al. Meat and meat-related compounds and risk of prostate cancer in a large prospective cohort study in the United States. Am J Epidemiol. 2009;170(9):1165-1177.

16. Friedenreich CM, Neilson HK, Lynch BM. State of the epidemiological evidence on physical activity and cancer prevention. Eur J Cancer. 2010;46(14):2593-2604.

17. Ma Y, Zhang P, Wang F, Yang J, Liu Z, Qin H. Association between vitamin $\mathrm{D}$ and risk of colorectal cancer: a systematic review of prospective studies. J Clin Oncol. 2011;29(28):3775-3782.

18. Schwartz GG. Vitamin D in blood and risk of prostate cancer: lessons from the Selenium and Vitamin E Cancer Prevention Trial and the Prostate Cancer Prevention Trial. Cancer Epidemiol Biomarkers Prev. 2014;23(8):1447-1449.

19. Liu Y, Tang W, Wang J, et al. Association between statin use and colorectal cancer risk: a meta-analysis of 42 studies. Cancer Causes Control. 2014;25(2):237-249.

20. Jespersen CG, Norgaard M, Friis S, Skriver C, Borre M. Statin use and risk of prostate cancer: a Danish population-based case-control study, 1997-2010. Cancer Epidemiol. 2014;38(1):42-47.

21. Din FV, Theodoratou E, Farrington SM, et al. Effect of aspirin and NSAIDs on risk and survival from colorectal cancer. Gut. 2010; 59(12):1670-1679.

22. Jacobs EJ, Rodriguez C, Mondul AM, et al. A large cohort study of aspirin and other nonsteroidal anti-inflammatory drugs and prostate cancer incidence. J Natl Cancer Inst. 2005;97(13):975-980.

23. Kirchhoff T, Kauff ND, Mitra N, et al. BRCA mutations and risk of prostate cancer in Ashkenazi Jews. Clin Cancer Res. 2004; 10(9):2918-2921.

24. Drucker L, Stackievitz R, Shpitz B, Yarkoni S. Incidence of BRCA1 and BRCA2 mutations in Ashkenazi colorectal cancer patients: preliminary study. Anticancer Res. 2000;20(1B):559-561.

25. Raymond VM, Mukherjee B, Wang F, et al. Elevated risk of prostate cancer among men with Lynch syndrome. J Clin Oncol. 2013; 31(14):1713-1718.

26. Giardiello FM, Allen JI, Axilbund JE, et al. Guidelines on genetic evaluation and management of Lynch syndrome: a consensus statement by the US Multi-Society Task Force on colorectal cancer. Gastroenterology. 2014;147(2):502-526.

27. Verras M, Sun Z. Roles and regulation of Wnt signaling and beta-catenin in prostate cancer. Cancer Lett. 2006;237(1):22-32.

28. Segditsas S, Tomlinson I. Colorectal cancer and genetic alterations in the Wnt pathway. Oncogene. 2006;25(57):7531-7537. 
29. Conteduca V, Sansonno D, Russi S, Dammacco F. Precancerous colorectal lesions (Review). Int J Oncol. 2013;43(4):973-984.

30. Qin M, Ma LQ, Tan J, et al. Risk factors for colorectal neoplasms based on colonoscopy and pathological diagnoses of Chinese citizens: a multicenter, case-control study. Int J Colorectal Dis. 2015;30(3):353-361.

31. Loberg M, Kalager M, Holme O, Hoff G, Adami HO, Bretthauer M. Long-term colorectal-cancer mortality after adenoma removal. $N$ Engl J Med. 2014;371(9):799-807.

32. Gopalswamy N, Shenoy VN, Choudhry U, et al. Is in vivo measurement of size of polyps during colonoscopy accurate? Gastrointest Endosc. 1997;46(6):497-502.

33. Lieberman DA, Rex DK, Winawer SJ, et al. Guidelines for colonoscopy surveillance after screening and polypectomy: a consensus update by the US Multi-Society Task Force on Colorectal Cancer. Gastroenterology. 2012;143(3):844-857.

34. Schymura MJ, Sun L, Percy-Laurry A. Prostate cancer collaborative stage data items - their definitions, quality, usage, and clinical implications: A review of SEER data for 2004-2010. Cancer. 2014;120 Suppl 23: 3758-3770.

35. Kishikawa H, Sato K, Yamauchi T, et al. Incidence and risk factors for colorectal neoplasia in patients with oral squamous cell carcinoma. Colorectal Dis. 2014;16(11):888-895.

36. Yoo HM, Gweon TG, Seo HS, et al. Role of preoperative colonoscopy in patients with gastric cancer: a case control study of the prevalence of coexisting colorectal neoplasms. Ann Surg Oncol. 2013;20(5):1614-1622.
37. Hiripi E, Bermejo JL, Sundquist J, Hemminki K. Association of colorectal adenoma with other malignancies in Swedish families. $\mathrm{Br} \mathrm{J}$ Cancer. 2008;98(5):997-1000.

38. Van Hemelrijck M, Feller A, Garmo H, et al. Incidence of second malignancies for prostate cancer. PLoS One. 2014;9(7):e102596.

39. Giovannucci E, Michaud D. The role of obesity and related metabolic disturbances in cancers of the colon, prostate, and pancreas. Gastroenterology. 2007;132(6):2208-2225.

40. Lilja H. Biology of prostate-specific antigen. Urology. 2003;62(5 Suppl 1): 27-33.

41. Thompson IM, Pauler DK, Goodman PJ, et al. Prevalence of prostate cancer among men with a prostate-specific antigen level $<$ or $=4.0 \mathrm{ng}$ per milliliter. $N$ Engl J Med. 2004;350(22):2239-2246.

42. Skolarus TA, Wolf AM, Erb NL, et al. American Cancer Society prostate cancer survivorship care guidelines. CA Cancer J Clin. 2014;64(4):225-249.

43. Sharp HJ, Swanson DA, Pugh TJ, et al. Screening colonoscopy before prostate cancer treatment can detect colorectal cancers in asymptomatic patients and reduce the rate of complications after brachytherapy. Pract Radiat Oncol. 2012;2(3):e7-e13.
OncoTargets and Therapy

\section{Publish your work in this journal}

OncoTargets and Therapy is an international, peer-reviewed, open access journal focusing on the pathological basis of all cancers, potential targets for therapy and treatment protocols employed to improve the management of cancer patients. The journal also focuses on the impact of management programs and new therapeutic agents and protocols on

\section{Dovepress}

patient perspectives such as quality of life, adherence and satisfaction. The manuscript management system is completely online and includes a very quick and fair peer-review system, which is all easy to use. Visit http://www.dovepress.com/testimonials.php to read real quotes from published authors. 